\section{Questión}

Periodismo / Comunicación ISSN 1669-6581
- Av. $44 \mathrm{~N}^{\circ} 676,1^{\circ}$ piso

CP 1900 - La Plata - Argentina

www.perio.unlp.edu.ar/question

La fragilidad de la esperanza: Reflexiones sobre y desde la educación en tiempos de pandemia.

Magalí Catino, Soledad Gómez y Margarita Eva Torres

DOI: https://doi.org/10.24215/16696581e279

\title{
La fragilidad de la esperanza: Reflexiones sobre y desde la educación en tiempos de pandemia.
}

\section{The fragility of hope: Reflections on and from pandemic education.}

\author{
Margarita Eva Torres \\ Prof. en Comunicación Social (FPyCS), Prof. Adjunta a cargo del Taller de Producción Textual (FPs-UNLP) \\ Magalí Catino / magali.catino@gmail.com \\ Prof. en Ciencias de la Educación (FHyCE-UNLP), Titular ordinaria, Pedagogía Cátedra 1, FPyCS \\ Soledad Gómez \\ Prof. en Comunicación Social (FPyCS-UNLP), Ayudante Diplomada Pedagogía Cátedra 1, FPyCS.
}

"La etimología del término pandemia dice exactamente eso: reunión del pueblo. La tragedia es que, en este caso, para demostrar solidaridad lo mejor es aislarnos y evitar tocar a otras personas. Es una extraña comunión de destinos. ¿Serán posibles otras?” (de Sousa Santos, B.

(2020:23)

Desde la perspectiva de la comunicación y la educación, este artículo pretende reflexionar sobre el momento histórico en el que se inscribe nuestra existencia y nuestro quehacer como mujeres / madres / profesionales ... interpeladas y sacudidas por una circunstancia global insospechada.

La pandemia emerge como un incidente, algo que irrumpe y detiene el curso de las rutinas y de pronto el mundo -signado por la silenciosa autoexplotación, la desigualdad y un sistema económico depredador-, se ve fuertemente sacudido y estrepitosamente situado frente al abismo de la propia construcción de su humanidad saqueada. Es que, "cuando la perturbación, en este caso disruptiva, coloca el imperativo de la transmisión, que es la que nos permite situarnxs en el reconocimiento del otrx, la conmoción no nos puede ser indiferente" (Catino, 2013: p.18). 
El nuevo incidente -enemigo invisible como lo llamaron los medios de todo el mundo- produjo un cimbronazo a gran escala y en todas las dimensiones de la vida.

Frente a una brutal incertidumbre, nos vimos obligadxs a detenernos y no quedó otra posibilidad que observar(nos). Nos quedamos frente a nosotrxs mismos, tratando de entender lo inentendible, de aceptar lo inaceptable: la fragilidad y la contingencia de la humanidad.

¿Cómo habitar un momento que, además de que nxs cala profundo, no nxs ofrece memorias a las cuales apelar para situarnos? Nxs quedamos estáticxs frente al asombro, al borde del precipicio, hundidxs en el desconcierto. Abruptamente quieta la inquietud de búsqueda.

Pero el mandato urgente de seguir haciendo, de buscar los modos de continuar con la vida productiva como si nada pasara es "un signo de pánico que se traduce en un estado de intensidad motivado por el miedo a algo que implica un peligro masivo sin ninguna posibilidad de enfrentarlo" (Kaufman, 2020: s/p.).

El estado de alerta permanente en que vivimos, que se manifiesta, por ejemplo, en la presión laboral, fue bien descripto por Han (2017) cuando caracterizó a la sociedad contemporánea como una "sociedad del rendimiento" que deviene en una "sociedad del dopaje".

La exigencia por un hacer casi desesperado se volvió más tangible en el marco de la pandemia y la respuesta humana se opone a la señal del planeta y no hace otra cosa que reaccionar con las mismas lógicas del rendimiento y la autoexigencia desmedida.

Entonces es necesario preguntar/nos ¿no será esta humanidad la versión póstuma de lo inhumano? ¿Por qué nos cuesta tanto detenernos y mirar (nos)? ¿No toleramos lo que emerge cuando el artificio libera todo lo obturado por la inercia existencial?

La conciencia de la muerte se vuelve más nítida y no hay placebo que pueda mitigarla. Las respuestas fetichistas se derrumban y nos quedamos desnudos frente a la pregunta imposible de formular ¿Cuál es el sentido de la humanidad?

El fantasma del ego se derrite y ya no hay de dónde sujetarse. Entonces, desvalidx, el ser humano vuelve su mirada y se encuentra en otra igual de suplicante, en un cuerpo igual de vulnerable. Los miedos, exacerbados por el discurso mediático hegemónico, introducen al sujetx en una vorágine sin límites, donde debe forzar al máximo su capacidad de autosostenimiento.

Las lógicas humanas que se observan frente a la pandemia sugieren que no hacemos otra cosa que escapar, pergeñar nuevos modos de actividad para no pensar lo que acontece. En 
ese sentido, Kaufman advierte sobre la necesidad de "oponerse al pánico" que "es un ejercicio de serenidad, aunque se tenga miedo, porque no somos héroes" (2020, s/p.).

No puede darse ningún cambio histórico que no implique la producción de "nuevas significaciones y la transformación de las prácticas sociales de la gente de acuerdo con diferentes definiciones y ritmos" (Hall, 2017, p: 71).

El sacudón existencial de la pandemia nos ofrece un terreno propicio para insistir en la necesidad del retorno hacia la condición humana y a la vida cotidiana, que es la dimensión donde el ser y el estar de la existencia le impone inteligibilidad al mundo y porque "las prácticas sociales no existen fuera de las significaciones que negociamos para ellas, las significaciones a través de las cuales y con las cuales vivimos (Hall, 2017, p:81).

Propiciamos una reflexión que tiene el horizonte puesto en la generación de nuevas prácticas epistémicas, nuevas formas de estar en el espacio, de decir, de narrar, de ser, formar subjetividades comprometidas éticamente. Quizá sea el momento de la indisciplina como acto emancipador, promover el entreaprendizaje y resignificar la emergencia, pero salirse de las formas parametrizadas del pensar implica un trabajo intersubjetivo, donde hasta el propio sentido de lo humano vuelva a resignificarse.

Es imperioso recuperar la humanidad en un mundo que manifiesta la radical inhumanidad, de lo no nombrado. Mélich nos señala que "la subjetividad se convierte en subjetividad humana no solamente cuando el sujeto individual es capaz de decidir cómo debe ser y cómo orientar su vida, sino también cuando es capaz de dar cuenta, además, de la vida del otrx, cuando responde por el otrx, de su sufrimiento y de su muerte" (2000: p. 17).

Al parecer, el contexto global nos ofrece la posibilidad de rearmar el mundo y en esa construcción todxs contamos con un tramo de herramientas y de condición humana para aportar. Romper el discurso unidimensional que pone al coronavirus en un lugar de síntesis totalizadora, es una tarea subjetiva de reconocimiento de lo posible. Tenemos ante nuestros ojos un mundo desconocido, ante el cual no tenemos respuestas, apenas si podemos esgrimir alguna pregunta, porque ante la plena incertidumbre se debilitan también las posibilidades de lo preguntable.

El aislamiento es hoy prescriptivo, pero las lógicas individualistas en las que funcionamos ya contribuian, desde antes, a la invisibilización del otrx. $Y$ en ese proceso el asombro doloroso de la imagen de un colectivo humano, del que somos protagonistas, partícipes y responsables. 
Movidxs intempestivamente a detenernos, pareciera una contradicción que no lo es. Y ese radical movimiento de quietud, nos sitúa en un abrir y cerrar de ojos en el proceso de transmutar la quietud inquieta, en inquietud quieta. Absoluto movimiento del estar y vertiginoso sinsentido del ser, que pendula en una brecha necesaria e insalvable de el/la paralaje que nos constituye. Nos encontramos despojadxs en el incierto camino de lo intangible, habitando la inquietud quieta, que logra el vacío del encuentro.

Somos pura natalidad todos los días...que son ahora, que siempre es hoy. Porque la radical existencia en esta cotidianeidad planetaria hoy nos sitúa inéditamente en que somxs todxs yo/tú, y la única sensación de certeza es la fragilidad y la finitud. Y surge la pregunta por la posibilidad de un mundo por venir que está en nuestras manos casi de manera hilarante en su pura presencia, y entonces queda comprender y comprometernos con un acontecimiento que exige un verdadero denuedo, para reinventar las formas de estar juntxs, que son ahora porque el tiempo no existe...

Lejos de alimentar los pesimismos, la pregunta es cómo transformar las situaciones de injusticia en la articulación epistémica y práctica. El futuro dependerá, en gran medida, del ejercicio individual y social de no aceptar la realidad como algo dado y al tiempo no sólo como un eterno fluir, sino como un momento en el que el ser humano, la esperanza del mundo en términos de Freire, (1993) pueda resurgir y reinventarse.

Somos educadoras con muy poco equipaje. Sólo tenemos la plena certeza de la incertidumbre (hoy más que nunca), realizando una tarea como la educación (que trabaja con la posibilidad de lo que no es) intentando formar la condición humana.... movidas por la esperanza tejida de fragilidad.

\section{Bibliografía:}

Catino, M. (2013) Sobre la incalculable trama del estar juntos: la condición humana en situación de catástrofe. Revista Question. pp. 17-21.

de Sousa Santos, B. (2020). La cruel pedagogía del virus. CLACSO, Buenos Aires Argentina. Freire, P. (1993) Política y educación. Siglo XXI Editores. Buenos Aires.

Hall, S. (2017) Estudios culturales 1983. Una historia teorética. Buenos Aires. Paidós. Han, Byung-Chul (2012). La sociedad del cansancio. Herder Editorial, S.L. Barcelona 
Kaufman, A. (2020) Entrevista periodística 27 de abril. Recuperada de: http://provinciaradio.com.ar/index.php/2020/04/27/alejandro-kaufman-sobre-la-pandemia-losmedios-suscitan-el-panico/

Melich, J. (2000). La educación como acontecimiento ético. Natalidad, narración y hospitalidad. Paidos. 